\title{
AVALIAÇÃO MICROESTRUTURAL DE UMA LIGA DE ALUMÍNIO 5052 H34 UTILIZADA EM BLINDAGEM MULTICAMADA*
}

\author{
Thales Moreira de Azevedo ${ }^{1}$ \\ Wesley Soares Braga ${ }^{2}$ \\ Ana Alice Gomes Lavatori ${ }^{3}$ \\ Leandro Guimarães de Oliveira ${ }^{4}$ \\ Fábio de Oliveira Braga ${ }^{5,6}$ \\ Pedro Henrique Lameirão Machado Lopes ${ }^{7}$ \\ Monique Osório Talarico da Conceição ${ }^{8}$ \\ Sergio Neves Monteiro ${ }^{9}$
}

\section{Resumo}

Dentre as ligas de alumínio, a liga 5052 tem sido bastante pesquisada para aplicações em altas taxas de deformação, devido à sua alta resistência mecânica, plasticidade e tenacidade. No presente trabalho foi investigada a microestrutura e a microdureza de uma liga 5052 H34. Esta foi submetida ao impacto balístico com munição $7.62 \mathrm{~mm}$, quando fazia parte da camada posterior de um sistema de blindagem multicamada composto também por um material cerâmico e um compósito. Observou-se um aumento na microdureza da liga, entretanto, não foram observadas alterações na microestrutura. $O$ aspecto de fratura da liga na alta taxa de deformação foi comparado com o de uma amostra fraturada em ensaio de tração. Observou-se um comportamento plástico ainda mais pronunciado no ensaio balístico.

Palavras-chave:Liga de alumínio 5052 H34; Microestrutura; Alta taxa de deformação; Blindagem multicamada.

\section{MICROSTRUCTURAL EVALUATION OF A 5052 H34 ALUMINUM ALLOY USED IN MULTILAYARED ARMOR}

\section{Abstract}

Among the aluminum alloys, the 5052 has been extensively researched aiming high rate deformation applications, due to its high mechanical strength, plasticity and toughness. In the present work, the microstructure and microhardness of a $5052 \mathrm{H} 34$ alloy were investigated. It was subjected to ballistic impact with $7.62 \mathrm{~mm}$ ammunition as back layer of a multilayered armor system composed of a ceramic and a composite material. An increase in the microhardness was observed, however, changes in the microstructure were not observed. The fracture aspect of the alloy in the high deformation rate was compared to the fracture of a tensile test fractured sample. It was observed stronger plastic behavior in the ballistic test specimen.

Keywords: Aluminum alloy 5052 H34; Microstructure; High deformation rate, multilayered armor.

1 Estudante, Graduação Tecnológica em Processos Metalúrgicos, Faculdade SENAl Rio, Rio de Janeiro, RJ e Brasil.

2 Estudante, Graduação Tecnológica em Processos Metalúrgicos, Faculdade SENAI Rio, Rio de Janeiro, RJ e Brasil.

3 Técnico de Serviços Tecnológicos, Laboratório de Ensaios Mecânicos e Microestruturais, Instituto SENAI de Tecnologia Solda (IST), Rio de Janeiro, Brasil. 
4 Técnico de Serviços Tecnológicos, Laboratório de Ensaios Mecânicos e Microestruturais, Instituto SENAI de Tecnologia Solda (IST), Rio de Janeiro, Brasil.

5 Engenheiro Metalurgista, M.Sc., Candidato ao Doutorado em Ciência dos Materiais, Seção de Engenharia Mecânica e de Materiais, Instituto Militar de Engenharia, Rio de Janeiro, RJ, Brasil. fabio_obraga@yahoo.com.br.

6 Engenheiro Metalurgista, M.Sc., Docente, Graduação Tecnológica em Processos Metalúrgicos, Faculdade SENAI Rio, Rio de Janeiro, RJ, Brasil.

7 Estudante, Graduando em Engenharia, Seção de Engenharia Mecânica e de Materiais, Instituto Militar de Engenharia, Rio de Janeiro, RJ, Brasil..

8 Física, D.Sc., Docente, Especialização em Engenharia de Soldagem, Faculdade SENAI Rio, Rio de Janeiro, RJ e Brasil.

9 Engenheiro, Ph.D., Docente, Seção de Engenharia Mecânica e de Materiais, Instituto Militar de Engenharia, Rio de Janeiro, RJ, Brasil. 


\section{INTRODUÇÃO}

A segurança pessoal é um assunto que muito preocupa os cidadãos das nações democráticas. Como reflexo, grandes investimentos têm sido realizados em métodos preventivos ou amenizadores dos riscos, tendo como um de seus principais exemplos os materiais para blindagem balística [1-3].

Um dos grandes desafios dessa área é o desenvolvimento de materiais leves para utilização em coletes balísticos. Pesquisas têm sido feitas considerando os sistemas de blindagens multicamada (SBM), que combinam as propriedades de diferentes materiais como forma de diminuir o peso das blindagens, sem que ocorra diminuição na proteção [4-8].

Um SBM típico possui uma camada frontal de material cerâmico, camada intermediária de material compósito e camada posterior de um metal dúctil. O cerâmico tem a capacidade de resistir à compressão exercida pelo projétil, possibilitando a fragmentação total ou parcial da sua ponta, e absorvendo a maior parte da energia contida. O compósito é capaz de coletar os fragmentos produzidos pelo cerâmico, e absorver parte da energia residual. O metal absorve o restante da energia dos fragmentos [5,9-11]. A camada posterior pode, portanto, ser composta de metais como o aço e alumínio.

Dentre as ligas de alumínio, a liga 5052 tem sido bastante pesquisada para aplicações em altas taxas de deformação, devido à sua alta resistência mecânica, alta plasticidade e tenacidade [12-13]. É uma liga Al-Mg, de uma série de ligas não tratáveis termicamente, mas que podem ser endurecidas por trabalho a frio, como 0 tratamento H34 [14].

A interação de projéteis que se movem em alta velocidade com alvos em repouso pode ser descrita pelas equações de conservação de Rankine-Hugoniot, em conjunto com a equação de estado do material [15]. As equações de conservação de massa (Equação 1), momento (Equação 2), energia (Equação 3), e a equação de estado de um material (Equação 4) são apresentadas abaixo.

$$
\begin{gathered}
\rho_{o} U_{s}=\rho\left(U_{s}-U_{p}\right) \\
\left(P-P_{0}\right)=\rho_{0} U_{s} U_{p} \\
E-E_{0}=\frac{1}{2}\left(P+P_{0}\right)\left(V_{0}-V\right) \\
U_{S}=C_{0}+S_{1} U_{p}
\end{gathered}
$$

Onde: $\rho_{0}$ e $\rho$ são as densidades do meio antes e após o impacto; $\mathrm{P}_{0}$ e $\mathrm{P}$ as pressões; $E_{0}$ e $E$ as energias internas; $V_{0}$ e $V$ os volumes específicos; Up é a velocidade de partícula; Us é a velocidade da onda de choque; $S_{1}$ é um parâmetro empírico e $\mathrm{C}_{0}$ é a velocidade do som no material.

No caso em que o alvo possui duas camadas ou mais, a onda de choque gerada interage na interface entre as camadas. Neste caso, as equações de conservação tomam a forma a seguir (Equações 5 e 6 ).

$$
P_{2}=\rho_{02}\left(C_{2}+S_{2} U_{p 2}\right) U_{p 2}
$$




$$
P_{1}=\rho_{01} C_{1}\left(V-U_{p 2}\right)+\rho_{01} S_{1}\left(V-U_{p 2}\right)^{2}
$$

A solução do sistema das equações 5 e 6 permite obter os valores de velocidade de partícula e de velocidade de onda de choque, para qualquer das interfaces estudadas. Este método é denominado "casamento de impedâncias".

É conhecido que a taxa de deformação à qual um material metálico está submetido pode causar mudança no mecanismo de deformação plástica, modificando a microestrutura pós-deformação, bem como propriedades como a tensão de escoamento e limite de resistência. Ocorre mudança de um movimento termicamente ativado das discordâncias, para um mecanismo dominado por arraste de fônons. [16].

Portanto, o objetivo do presente trabalho é investigar as alterações na estrutura e na propriedade de dureza de uma liga de alumínio 5052 H34, quando submetida a uma alta taxa de carregamento, referente ao impacto de um projétil $7,62 \mathrm{~mm}$ no SBM ao qual o alumínio faz parte.

\section{MATERIAIS E MÉTODOS}

Em trabalho anterior [8], foi estudado um SBM com camada frontal cerâmica $\left(\mathrm{Al}_{2} \mathrm{O}_{3}-4 \% \mathrm{Nb}_{2} \mathrm{O}_{5}\right)$ com $10 \mathrm{~mm}$ de espessura; camada intermediária de poliéster reforçado com 30\% de fibra natural de curauá, com $10 \mathrm{~mm}$ de espessura; e uma camada posterior de liga de alumínio 5052 H34, com 5 mm de espessura. A Figura 1 apresenta o SBM. A camada de alumínio será objeto do presente trabalho.

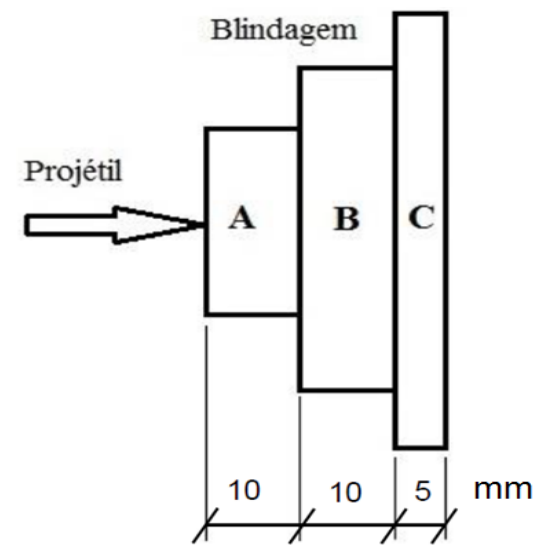

(a)

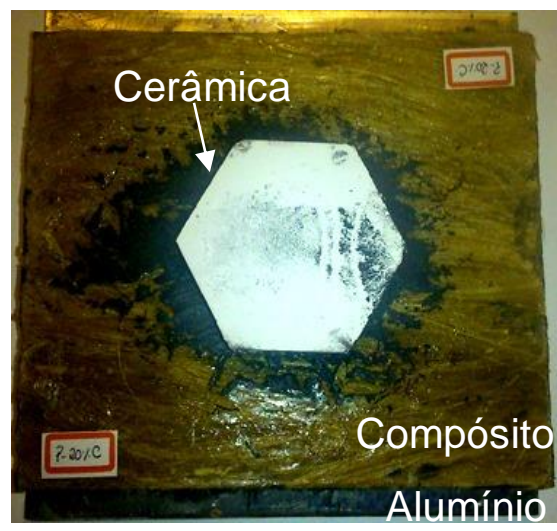

(b)

Figura 1. Blindagem multicamada: (a) Diagrama esquemático: $A$ é a camada cerâmica, B é o compósito, C é o alumínio; (b) corpo de prova final utilizado nos ensaios balísticos.

As placas de liga de alumínio 5052 H34 foram fornecidas pela empresa Metalak Metais Ltda, com dimensões 120 × $150 \times 5$ mm. Nas Tabelas 1 e 2, são mostradas informações as propriedades mecânicas e composição química da liga, respectivamente, conforme fornecidas pelo fabricante. 
Tabela 1. Propriedades Mecânicas da liga de alumínio utilizada.

\begin{tabular}{|c|c|c|}
\hline Propriedades & Valor & Especificação $^{1}$ \\
\hline Resistência à tração (MPA) & 249 & Min.235 Máx. 285 \\
\hline Tensão de escoamento (MPA) & 205 & Mín. 180 \\
\hline$\Delta \mathrm{L}_{\mathrm{L}}(\%)$ & 10 & Mín. 10 \\
\hline
\end{tabular}

${ }^{1}$ Fonte: ASM Inc., 2015 [17].

Tabela 2. Composição química da liga de alumínio 5052 H34, listada pelo fornecedor.

\begin{tabular}{|c|c|c|}
\hline Elemento & Concentração (\%peso) & Especificação (\%peso) \\
\hline $\mathrm{Mg}$ & 2,25 & Mín. 2,20 Máx. 2,80 \\
\hline $\mathrm{Fe}$ & 0,32 & Máx. 0,40 \\
\hline $\mathrm{Cr}$ & 0,16 & Mín. 0,15 Máx 0,35 \\
\hline $\mathrm{Si}$ & 0,20 & Máx. 0,25 \\
\hline $\mathrm{Cu}$ & 0,01 & Máx. 0,10 \\
\hline $\mathrm{Zn}$ & 0,01 & Máx. 0,10 \\
\hline
\end{tabular}

Fonte: ASM Inc., 2015 [17].

O SBM sofreu impacto balístico com munição 7,62 $\mathrm{mm}$, quando posicionado frente a um bloco de plastilina (Corfix), conforme esquema da Figura 2. Estes ensaios foram realizados no Centro de Avaliações do Exército (CAEx), Rio de Janeiro, com base em procedimentos da Norma NIJ 0101.06 (2008).

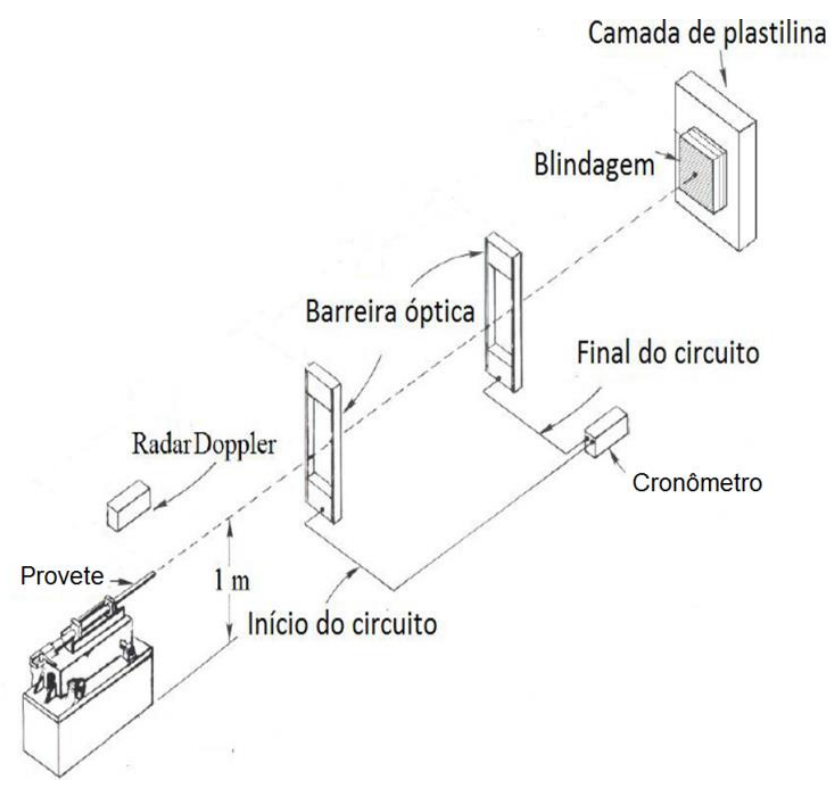

Figura 2. Esquema de montagem do ensaio balístico do SBM.

Após o ensaio balístico, a placa de alumínio deformada foi retirada da composição da blindagem, e teve sua microestrutura e propriedades estudadas. A Figura 3 mostra a placa deformada em comparação com uma placa não deformada. 


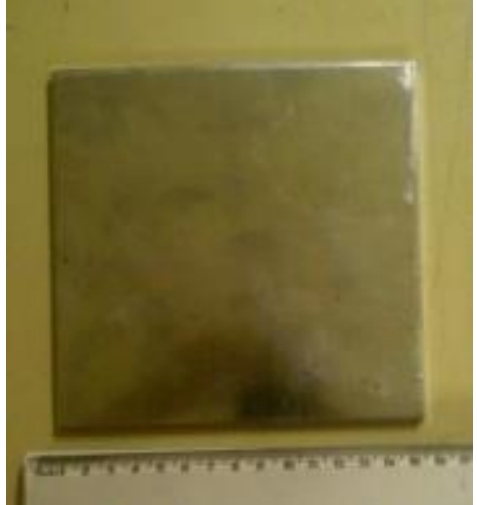

(a)

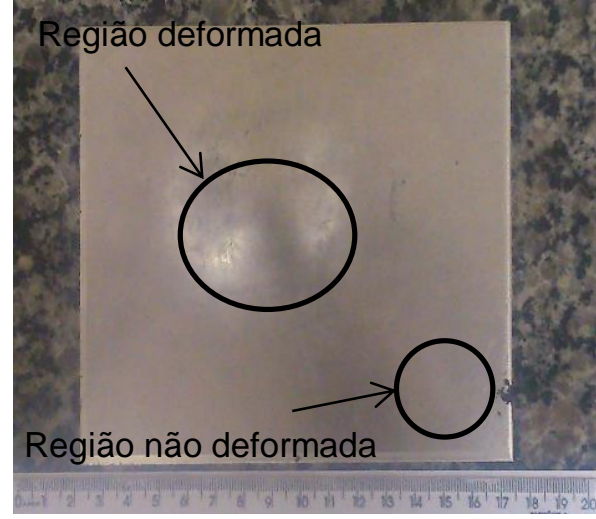

(b)

Figura 3. Placa de alumínio utilizada na camada posterior da blindagem: (a) chapa sem deformação; (b) chapa deformada pelo ensaio balístico.

Com o objetivo de comparar a microestrutura da área deformada e não deformada, foram retiradas quatro amostras da placa de alumínio após o ensaio balístico, sendo duas da região deformada e duas da região não deformada (Figura 4). Foram também examinadas diferentes orientações em relação ao plano da chapa, resultando nas seguintes amostras e designações: (a) Plano da chapa região sem deformação (PC-SD); Plano da chapa - região deformada (PC-DEF); E (b) análise ao longo da espessura da chapa: Plano transversal - região sem deformação (PT-SD); Plano transversal - região deformada (PT-DEF). Diferentes regiões das amostras foram analisadas, e estas podem ser observadas na Figura 4.

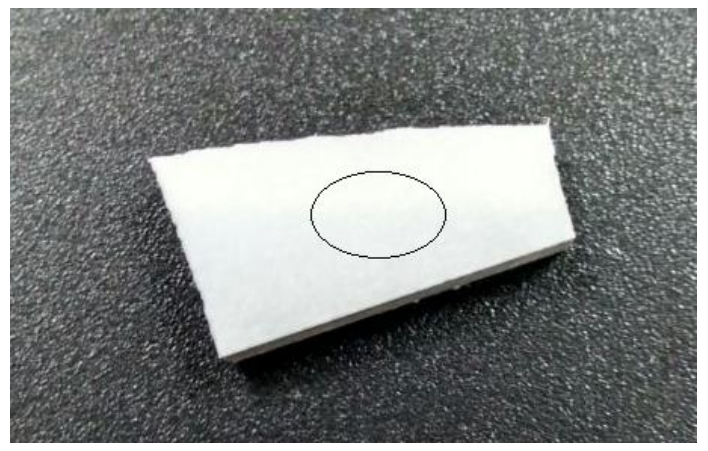

(a)

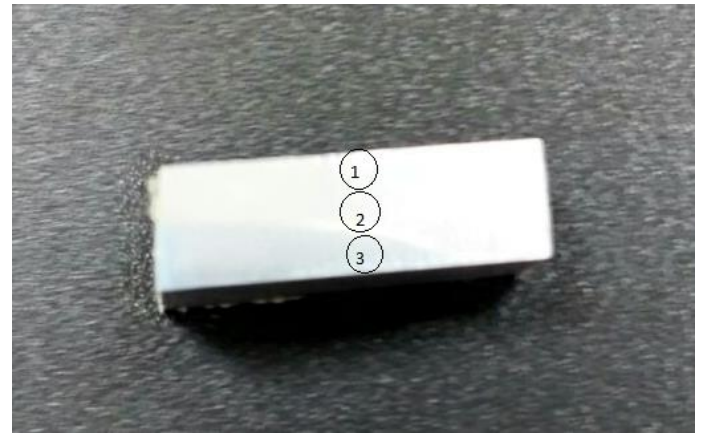

(a)

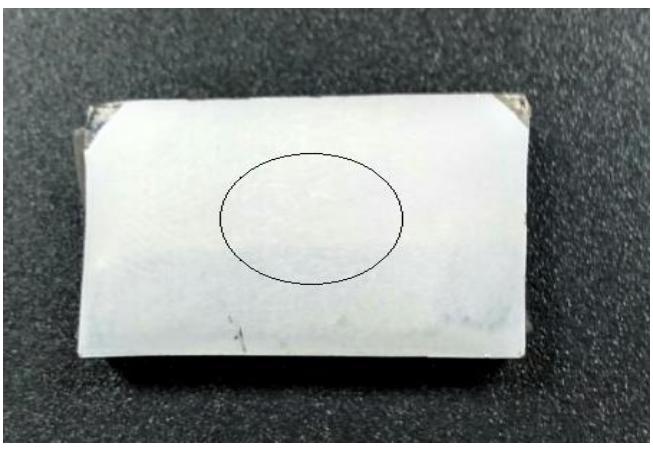

(b)

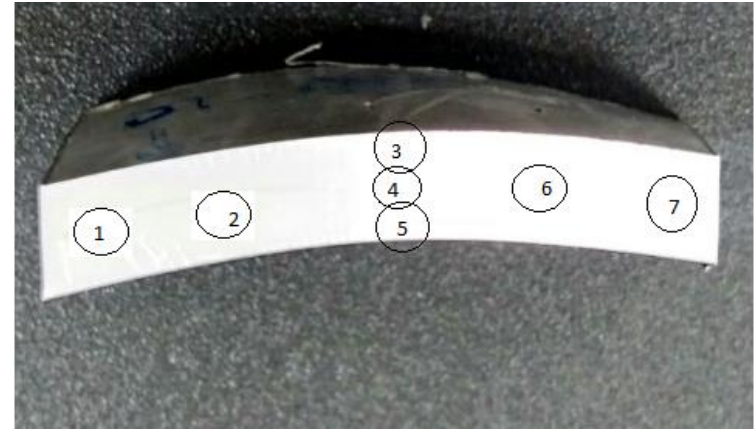

(b)

Figura 4. Amostras retiradas da placa deformada: (a) PC-SD; (b) PC-DEF; (c) PT-SD; (d) PT-DEF. 
Após o corte, foi realizada preparação metalográfica da superfície das amostras, por meio de lixamento até 2000 mesh, polimento com pasta de diamante de $1 \mu \mathrm{m}$, e ataque químico com o reagente Keller. As observações microestruturais foram realizadas com o microscópio óptico Olympus GX-51 nos aumentos de 100x e 1000x. O equipamento está disponível no Instituto SENAI de Tecnologia (IST) de Solda, Rio de Janeiro.

Os testes de microdureza Vickers foram realizados no microdurômetro Shimadzu HMV-G, nas regiões numeradas da Figura 4, utilizando $200 \mathrm{Kgf}$ como carga, e seguindo a norma NBR-6672. O equipamento está disponível no IST Solda.

Com a finalidade de se estudar também a fratura nas altas taxas de deformação, foi realizado um teste balístico em um SBM com a camada de alumínio mais fina, com $1 \mathrm{~mm}$, para que a peça sofresse a fratura, como mostra a Figura 5. Para fins de comparação, foi examinada também uma peça do mesmo material, fraturada em ensaio de tração, estudada por Braga (2015) [8]. A superfície de fratura foi examinada no microscópio eletrônico de varredura (MEV) Bruker Quanta 250, disponível no IST Solda.

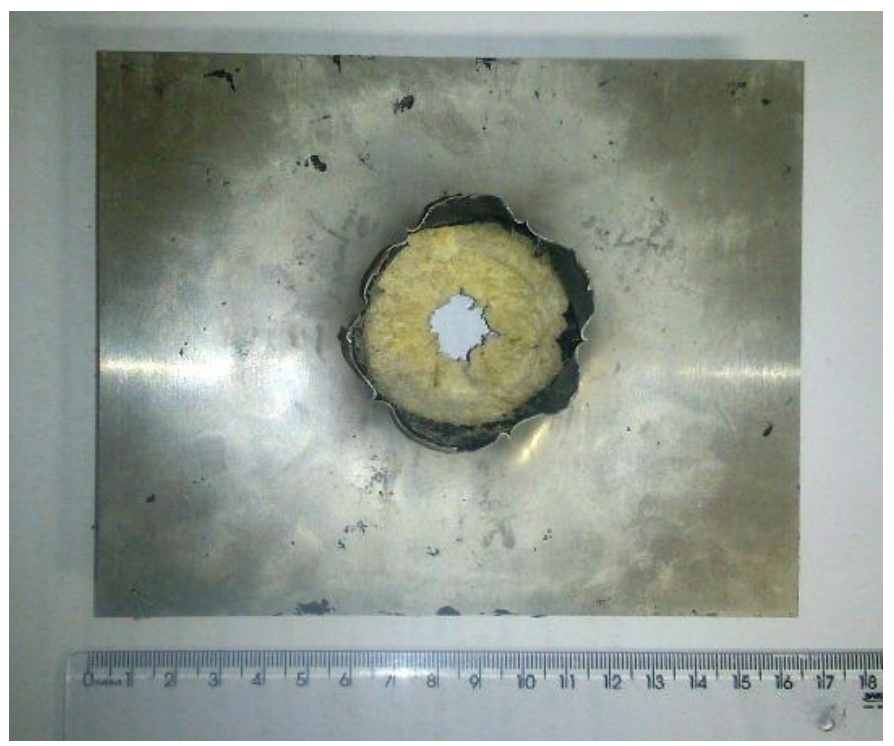

Figura 5. Parte posterior do SBM fraturado no ensaio balístico.

A taxa de deformação da liga no ensaio de tração foi estimada dividindo-se a velocidade de deslocamento da garra da máquina pela extensão total. A taxa de deformação da liga no ensaio balístico, por sua vez, foi estimada com base nos dados de velocidade de partícula $\left(U_{p}\right)$ obtidos teoricamente por Braga, 2015 [8], que se baseou nas relações de Hugoniot (Equações 5 e 6). Este valor foi dividido pelo raio da calota medido na amostra deformada. A Tabela 3 apresenta os resultados calculados.

Tabela 3. Valores da taxa de deformação nas amostras de tração e de ensaio balístico.

\begin{tabular}{|c|c|c|c|}
\hline Carregamento & $\begin{array}{c}\text { Velocidade } \\
(\mathbf{m} / \mathbf{s})\end{array}$ & $\begin{array}{c}\text { Extensão } \\
(\mathbf{m})\end{array}$ & $\begin{array}{c}\text { Taxa de } \\
\text { Deformação }\left(\mathbf{s}^{-1}\right)\end{array}$ \\
\hline Tração & $5,0.10^{-5}$ & 0,003 & $2,0.10^{-2}$ \\
\hline Ensaio Balístico & $2,5.10^{2}$ & 0,01 & $2,5.10^{4}$ \\
\hline
\end{tabular}




\section{RESULTADOS E DISCUSSÃO}

As Tabelas 4 e 5 apresentam os valores de microdureza nas diferentes seções da liga analisada.

Tabela 4. Microdureza Vickers das diferentes amostras da liga, medidas na região central e ao longo da espessura.

\begin{tabular}{|c|c|c|c|}
\hline Material & \multicolumn{3}{|c|}{ Microdureza(HV) } \\
\hline PC-SD & \multicolumn{3}{|c|}{$79 \pm 3$} \\
\hline PC-DEF & $83 \pm 2$ \\
\hline \multirow{2}{*}{ PT-SD } & Região 1 & Região 2 & Região 3 \\
\cline { 2 - 4 } & $82 \pm 2$ & $79 \pm 1$ & $79,6 \pm 0,1$ \\
\hline \multirow{2}{*}{ PT-DEF } & Região 3 & Região 4 & Região 5 \\
\cline { 2 - 4 } & $86 \pm 2$ & $81 \pm 2,0$ & $83 \pm 4$ \\
\hline
\end{tabular}

Tabela 5. Microdureza Vickers da amostra deformada por ensaio balístico (PT-DEF), a medida ao longo do arco da calota.

\begin{tabular}{|c|c|c|}
\hline Material & Região & Microdureza(HV) \\
\hline \multirow{4}{*}{ PT-DEF } & 1 & $80 \pm 1$ \\
\cline { 2 - 3 } & 2 & $82 \pm 3$ \\
\cline { 2 - 3 } & 4 & $81 \pm 2$ \\
\cline { 2 - 3 } & 6 & $80 \pm 2$ \\
\cline { 2 - 3 } & 7 & $82 \pm 4$ \\
\hline
\end{tabular}

Pode-se observar pela Tabela 4 que houve uma tendência de aumento na microdureza da liga mediante o impacto balístico, ou seja, a amostra PC-DEF apresentou maior microdureza que a PC-SD, e as regiões individuais ao longo da espessura da amostra PT-DEF, apresentaram maior microdureza que as respectivas regiões na amostra PT-SD. Este resultado era esperado devido ao aumento na densidade de defeitos estruturais (como discordâncias), pela deformação plástica ocorrida. Outra tendência observada foi a queda na microdureza, a partir de uma das extremidades, nas amostras do plano transversal. Este maior microdureza existe, provavelmente, devido ao contato desta extremidade com o laminador durante o trabalho a frio prévio da chapa (tratamento H34). Em relação ao arco da calota, não foi identificada variação na dureza, como já era esperado.

A microestrutura da liga, orientada no plano da chapa (PC), pode ser observada através da Figura 6. Podem ser observados grãos equiaxiais, e uma microestrutura formada por precipitados finos e inclusões não-metálicas em uma matriz contínua. A fase matriz é formada por solução sólida $\alpha$, rica em alumínio, e os precipitados são, provavelmente, de fase intermetálica $\mathrm{Al}_{3} \mathrm{Mg}_{2}$, com $37,3 \%$ de magnésio, ou de outros compostos intermetálicos, de alumínio com magnésio e impurezas como $\mathrm{Si}$ e $\mathrm{Cr}$ [14]. Os grãos em ambas as amostras se mostraram altamente deformados, podendo ser observadas bandas de deformação no interior dos grãos. É importante mencionar que as amostras aqui designadas "sem deformação" (como a PC-SD), são mais precisamente "sem deformação dinâmica", uma vez que foram previamente deformadas na laminação, no prévio tratamento mecânico H34. Portanto, mesmo na amostra PC-SD, pode-se observar os grãos altamente encruados. 


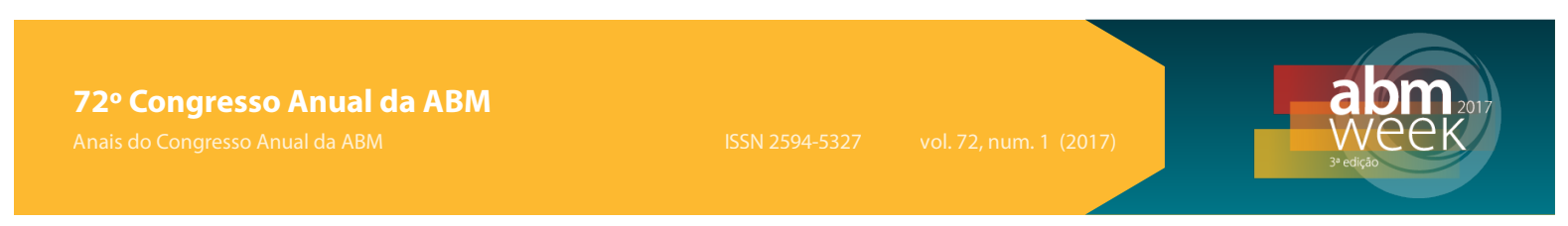

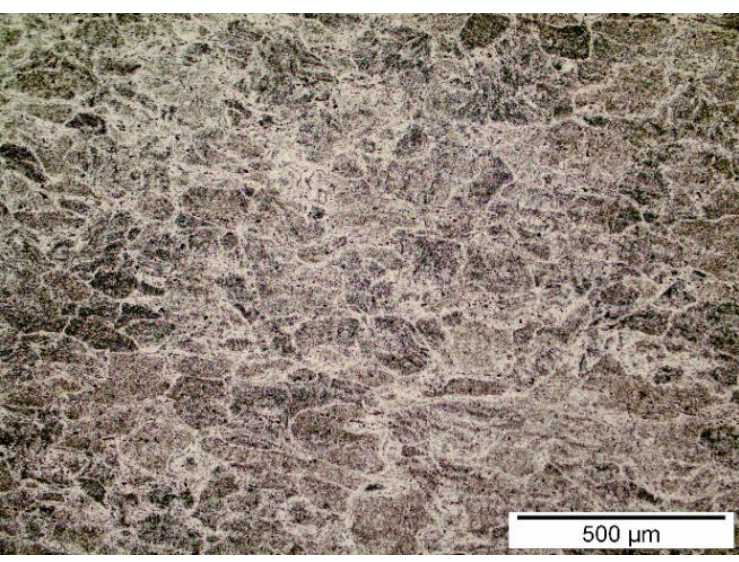

(a)

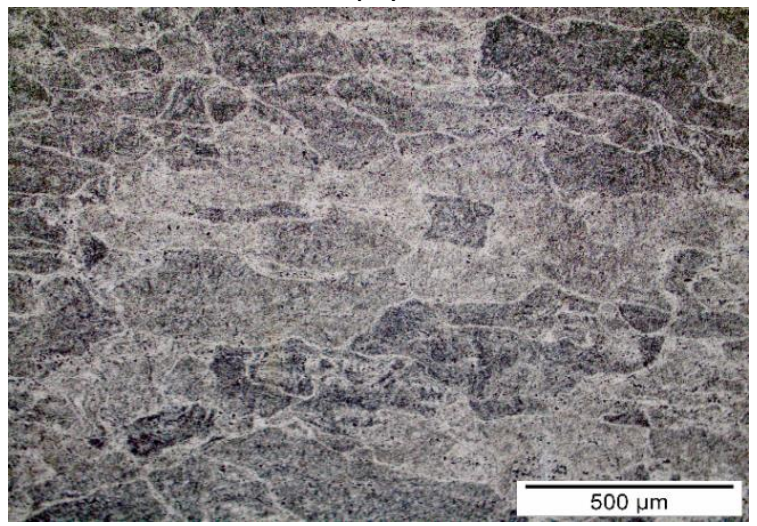

(c)

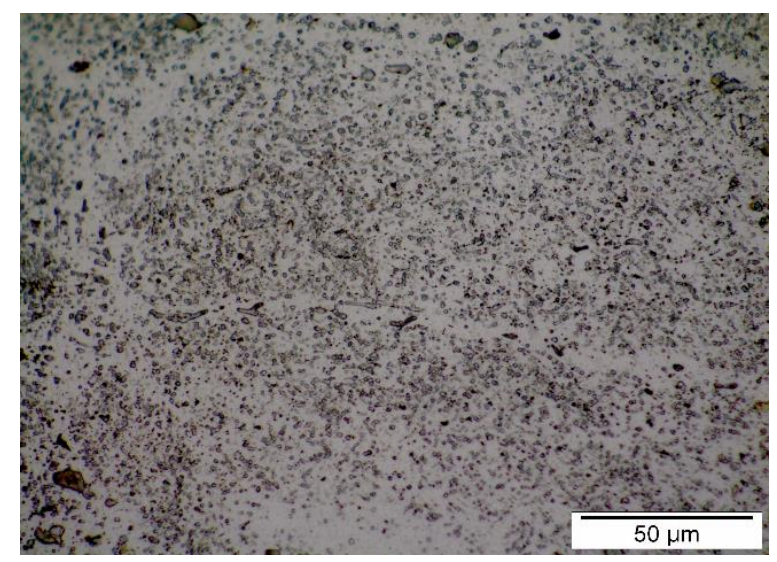

(b)

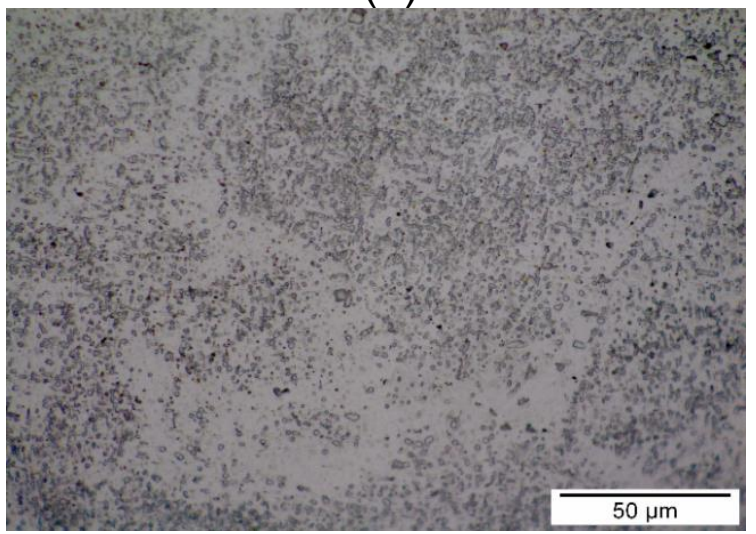

(d)

Figura 6. Microestrutura das amostras referentes ao plano da chapa: antes da deformação (PC-SD) (a) 100x e (b) 1000x; após a deformação (PC-DEF) (c) 100x; (d) 1000x.

Na Figura 7 é mostrada a microestrutura da liga ao longo do plano transversal (PT) da chapa (ao longo da espessura). Observa-se o alongamento dos grãos seguindo a direção de laminação, que é resultado do tratamento mecânico prévio H34. Um maior alongamento dos grãos foi observado na amostra PT-DEF em relação à PT-SD, devido à deformação adicional, proporcionada pelo impacto balístico. Observa-se também uma diminuição no tamanho das inclusões nas amostras deformadas dinamicamente, efeito também provocado pela deformação a frio. 


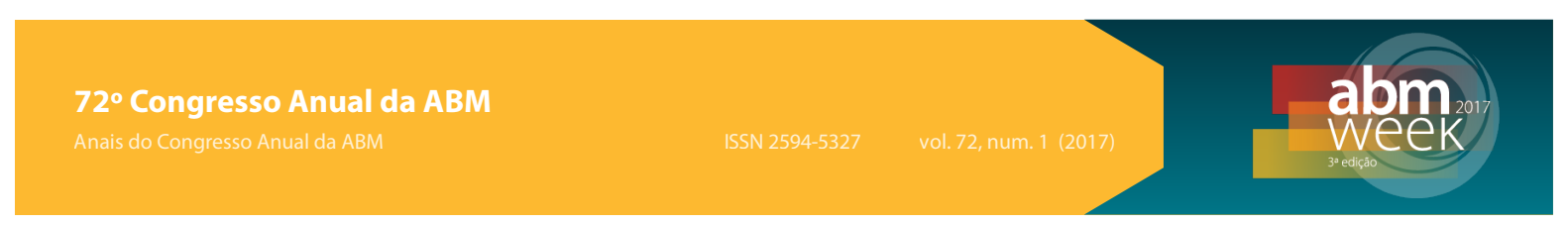

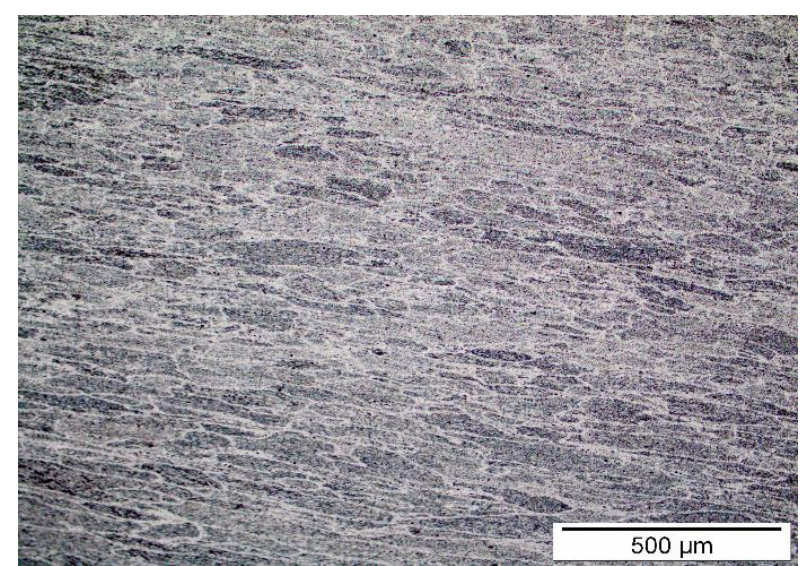

(a)

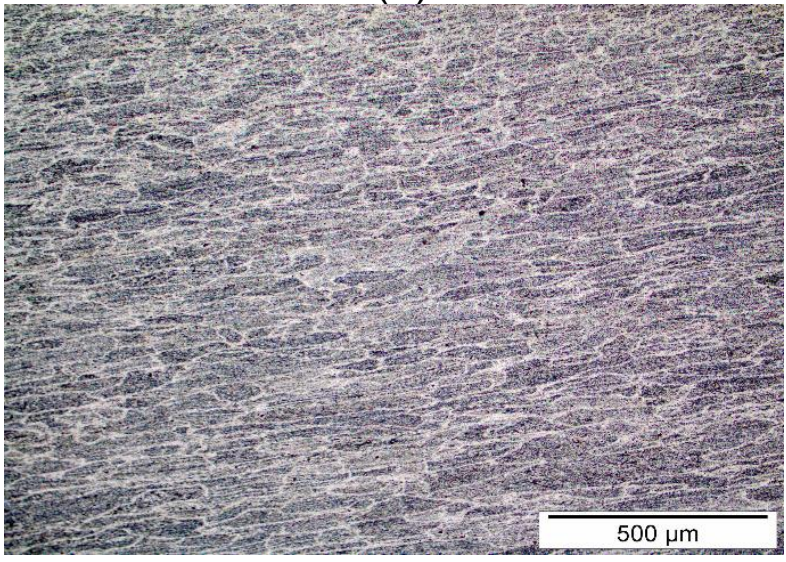

(c)

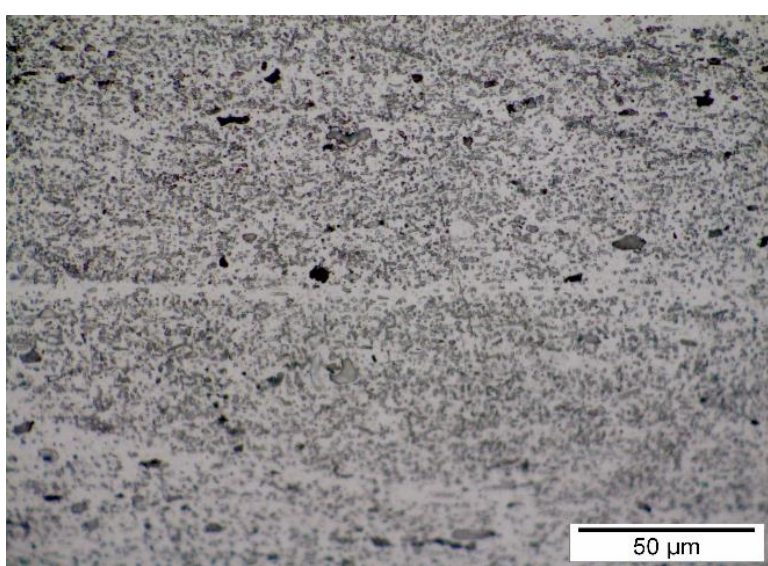

(b)

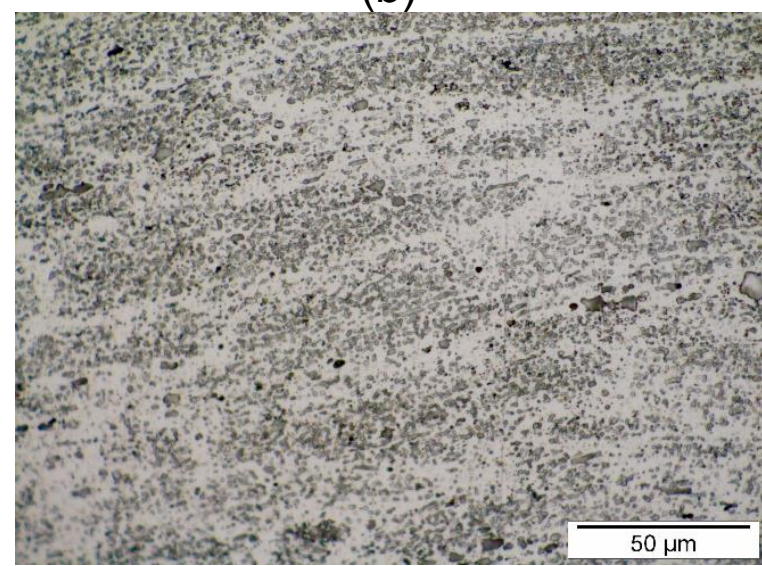

(d)

Figura 7. Microestrutura das amostras referentes ao plano transversal da chapa: antes da deformação (PT-SD) (a) 100x e (b) 1000x; após a deformação (PT-DEF) (c) 100x; (d) 1000x.

Na Figura 8 é mostrado aspecto de fratura da amostra deformada no ensaio de tração.
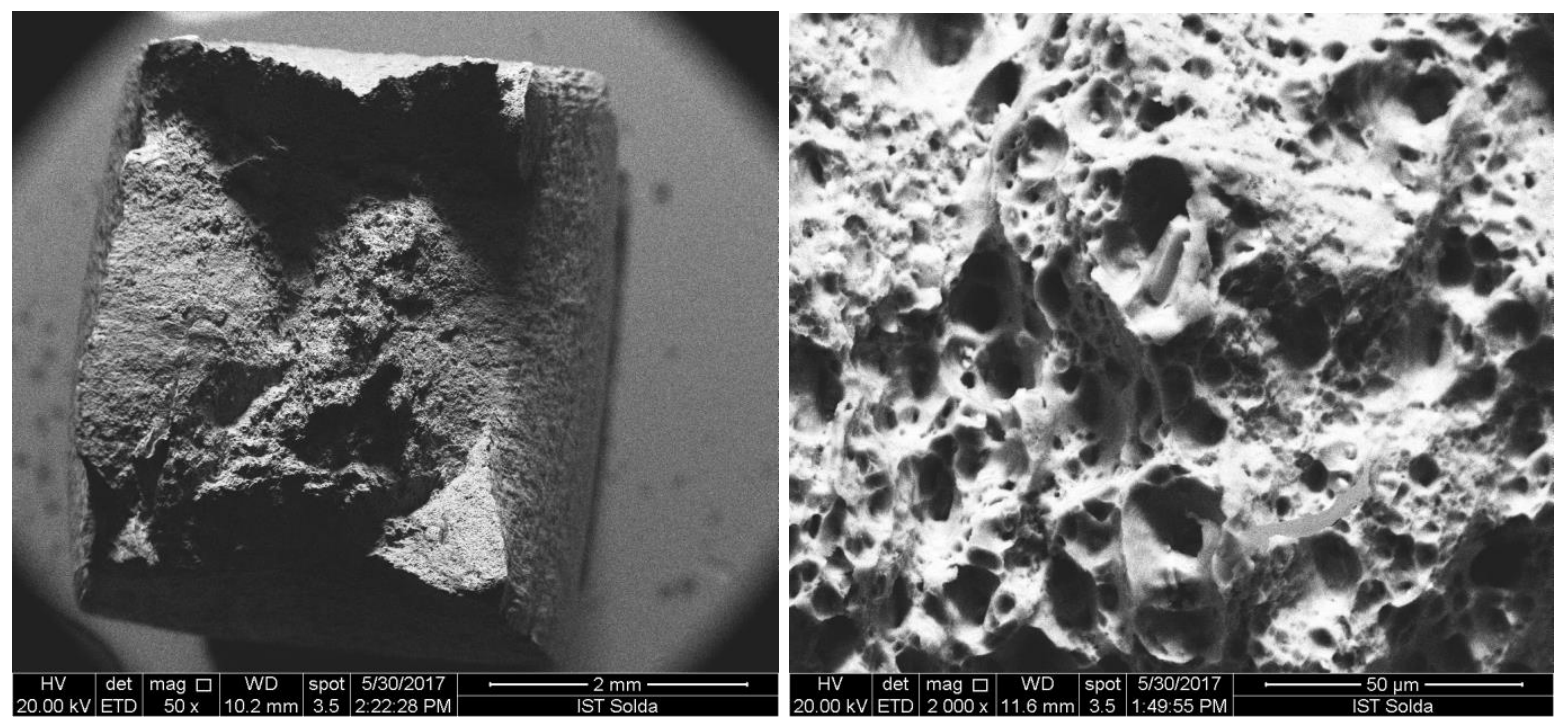

Figura 8. Aspecto de fratura da amostra deformada no ensaio de tração: (a) 50x; (b) 2000x. 
Na Figura 9 é mostrado aspecto de fratura da amostra deformada no ensaio balístico.
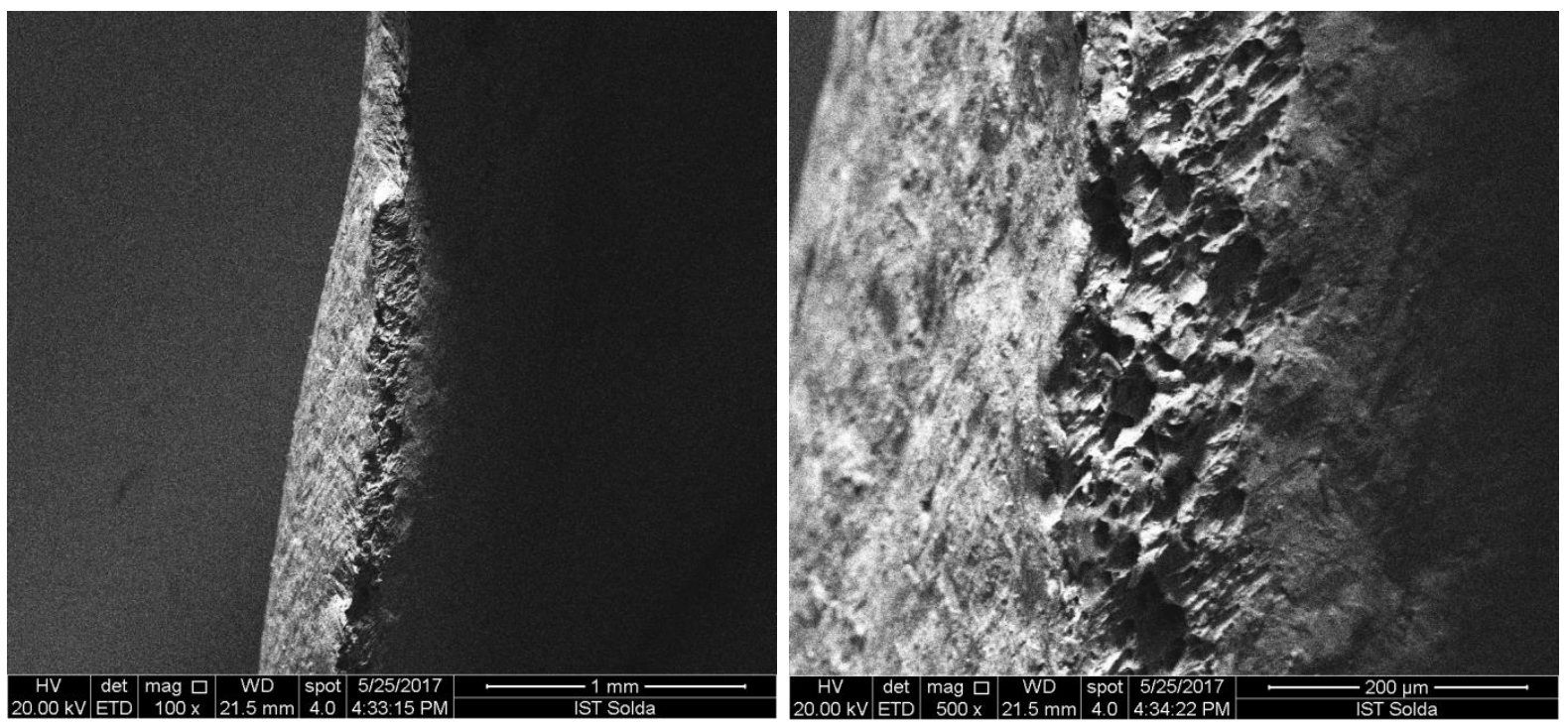

Figura 9. Aspecto de fratura da amostra deformada no ensaio de tração: (a) 100x; (b) 500x.

Pela Figura 8 pode-se observar a fratura tipicamente dúctil do alumínio, com característica "taça e cone" em menores aumentos, e com microcavidades (dimples) em maiores aumentos. Pela Figura 9 se observa que a alta taxa de deformação mantém, ou até amplia, a característica dúctil da fratura do alumínio. Podem ser observadas as microcavidades (Figura 9b), além de ocorrer grande diminuição da seção da placa. Neste caso, é interessante observar que a placa tinha, originalmente, $1 \mathrm{~mm}$ de espessura, e a seção de fratura tem apenas $150 \mu \mathrm{m}$ de espessura, caracterizando uma alta ductilidade do material. Pela Figura 8b também se observa que as microcavidades estão alongadas na direção superior-direita, indicando uma falha por cisalhamento, devido ao carregamento que o projétil executou.

\section{CONCLUSÕES}

- No presente trabalho foi investigada a microestrutura e a microdureza de uma liga 5052 H34, submetida ao impacto balístico com munição 7.62 mm, quando fazia parte da camada posterior de um sistema de blindagem multicamada.

- Ao longo do plano da chapa, a liga apresenta microestrutura equiaxial, contendo precipitados finos e inclusões não-metálicas em uma matriz contínua, antes e após a deformação dinâmica.

- Ao longo do plano transversal (espessura), a liga apresenta microestrutura orientada, contendo precipitados finos e inclusões não-metálicas em uma matriz contínua, antes e após a deformação dinâmica.

- Foram observadas características de uma estrutura encruada, mesmo antes da deformação dinâmica, resultante do tratamento mecânico prévio (H34).

- O impacto balístico provocou um pequeno aumento na microdureza da liga, devido ao acúmulo de defeitos estruturais resultantes da deformação plástica. 
- A liga mostrou grande plasticidade, especialmente, quando solicitada na alta taxa de deformação do ensaio balístico.

\section{Agradecimentos}

Os autores do presente trabalho agradecem ao IST Solda pela realização das análises microestruturais e de microdureza, e ao CNPq pelo fomento da pesquisa através do processo 159753 de 2015/05.

\section{REFERÊNCIAS}

1 Wang L, Kanelsalingam S, Nayak R, Padhye R. Recent Trends in Ballistic Protection. TLIST. 2014; 3:37-47.

2 U.S. Department of Justice. National Institute of Justice (NIJ). Guide Body Armor: Selection \& Application Guide 0101.06 to Ballistic-Resistant Body Armor. Washington, DC: 2014.

3 Hani ARA, Roslan A, Mariatti J, Maziah M. Body Armor Technology: A Review of Materials, Construction Techniques and Enhancement of Ballistic Energy Absorption. Adv. Mat. Res. 2012; 488-489:806-812.

4 Akella K, Naik NK. Composite armor - A review. J. Indian Inst. Sci.. 2015; 95(3):297312.

5 Monteiro SN, Lima Jr. EP, Louro LHL, Silva LC, Drelich JW. Unlocking Function of Aramid Fibers in Multilayered Ballistic Armor. Metall. Mater. Trans. A. 2014; 46a: 37-40.

6 Medvedovski E. Ballistic Performance of Armour Ceramics: Influence of Design and Structure. Part2. 2010; 36:2117-2127.

7 Medvedovski E. Lightweight Ceramic Composite Armour System. Adv. Appl. Ceram. 2006; 105(5):241-245.

8 Monteiro SN, Braga FO, Lima Jr. EP, Louro LHL, Drelich JW. Promising Curaua FiberReinforced Polyester Composite for High-Impact Ballistic Multilayered Armor. Polym. Eng. Sci. Published Online (2016) doi: 10.1002/pen.24471.

9 Tasdemirci A, Tunusoglu G, Güden M. The Effect of the Interlayer on the Ballistic Performance of Ceramic/Composite Armors: Experimental and Numerical Study. Int. J. Impact. Eng. 2012; 44:1-9.

10 Nayak N, Banerjee A, Sivaraman P. Ballistic Impact Response of Ceramic-faced Aramid Laminated Composites Against $7.62 \mathrm{~mm}$ Armour Piercing Projectiles. Def. Sci. J. 63(4):369-375.

11 Yadav S, Ravichandran G. Penetration Resistance of Laminated Ceramic/Polymer Structures. Int. J. Impact Eng. 2003; 28:557-574.

12 Masuda T, Kobayashi T, Toda H. High Strain Rate Deformation Behavior of Al-Mg Alloys. In: ICF10; 2001; Honolulu, USA. 2013.

13 Guo J, Li Y, Ding H. Modeling the flow of aluminum alloy 5052. In: ICMSE; 2015; Atlantis Press; 2015.

14 Hatch JE. Aluminum: Properties and Physical Metallurgy. ASM. Metals Park, USA, 1990.

15 Meyers MA. Dynamic Behavior of Materials. New York: John Wiley \& Sons; 1994.

16 Shu H, Huang X, Pan H, Zhang F, Xie Z, Ye J, Jia G. Plastic Behavior of Aluminum in High Strain Rate Regime. J. Appl. Phys. 116(033506):1-6.

17 ASM Aerospace Specification Metals Inc. Aluminum 5052 H34. ASM Material Data Sheet. Disponível em: <http://asm.matweb.com/search/SpecificMaterial.asp? bassnum=MA5052H34>. Acesso em: Jun. 2017. 